\title{
Diagnosing Hypertension in Primary Care Clinics According to Current Guidelines
}

\author{
Sarah Woolsey, MD, MPH, Brittany Brown, MPH, Brenda Ralls, PhD, \\ Michael Friedrichs, MStat, and Barry Stults, MD
}

Purpose: This descriptive study examines hypertension diagnostic practices in Utah primary care clinics relative to the 2015 US Preventive Services Task Force (USPSTF) recommendations for the accurate diagnosis of hypertension. We assessed clinic procedures in place to facilitate accurate in-office and outof-office blood pressure (BP) measurement.

Methods: An online questionnaire was administered to 321 primary care clinics. We compared current clinic BP measurement practices with the USPTF recommendations and assessed the level of adherence to the recommendations by level of clinic integration with a hospital.

Results: Of the 321 primary care clinics that received the assessment, $123(38.3 \%)$ completed the questionnaire. Clinics varied significantly in their ability to provide accurate in-office measurement, ranging from $57.5 \%$ to $\mathbf{9 3 . 5 \%}$ of clinics complying with USPSTF recommendations. Only $25.2 \%$ of clinics reported having access to ambulatory monitoring and $36.6 \%$ had instructional materials for accurate home BP monitoring. Clinics integrated with a hospital were more likely to report adherence to recommendations than solo or independent clinics $(36.4 \%$ vs $10.5 \% ; P<.01)$.

Conclusion: This assessment shows that many primary care clinics are not well prepared to implement the USPSTF guidelines for accurate diagnosis of hypertension. Most office practices will benefit from support to develop their capacities. (J Am Board Fam Med 2017;30:170-177.)

Keywords: Ambulatory Blood Pressure Monitoring, Blood Pressure, Hypertension, Primary Health Care, Surveys and Questionnaires, Utah

Inaccurate diagnosis of hypertension in the office setting is a major concern. First, multiple studies demonstrate that office staff most often measure blood pressure (BP) using incorrect technique. ${ }^{1-3}$ Because most technical errors falsely elevate BP, measurement by usual office staff averages $10 / 7$ $\mathrm{mmHg}$ higher than BP measured according to current guidelines. ${ }^{1,2}$ Second, systematic and narrative

This article was externally peer reviewed.

Submitted 2 April 2016; revised 13 October 2016; accepted 17 October 2016.

From HealthInsight Utah, Salt Lake City (SW); the Utah Department of Health (BB, BR, MF); and the Department of Medicine, University of Utah, Salt Lake City (BS).

Funding: Funding was provided in part by the Centers for Disease Control and Prevention Basic Implementation Heart Disease and Stroke Prevention Program Grant, and the State Public Health Actions to Prevent and Control Diabetes, Heart Disease, Obesity and Associated Risk Factors and Promote School Health Grant.

Conflict of interest: none declared.

Corresponding author: Sarah Woolsey, MD, MPH, HealthInsight Utah, 756 East Winchester, St, Suite 200, Salt Lake City, UT, 84107 (Email: swoolsey@healthinsight.org). reviews conclude that about $30 \%$ of patients with elevated BP measured in an office have isolated office ("white-coat") hypertension but normal BP out of the office. ${ }^{4,5}$ Considering 24-hour ambulatory $\mathrm{BP}$ monitoring $(\mathrm{ABPM})$ as the reference standard for an accurate hypertension diagnosis and prediction of future cardiovascular events, a large proportion of people with elevated in-office BP may be normotensive with out-of-office BP monitoring (ranging from $5 \%$ to $65 \%$ among 24 studies reviewed by Piper et al. ${ }^{4}$ ). A false-positive diagnosis of hypertension exposes patients and the health care system to the unnecessary costs of antihypertension medications and office visits, to the potential side effects of these medications, and, albeit with less certainty, to the possible adverse psychological effects from being labeled as "hypertensive." As a result, to avoid misdiagnosis and overtreatment, new US and international guidelines propose that office BP measurement (OBPM) be used only as a screening test for 
hypertension. ${ }^{6-10}$ These guidelines, including a 2015 grade A recommendation from the US Preventive Services Task Force, ${ }^{6}$ propose that, for most patients, confirmation of a diagnosis of hypertension should be achieved with out-ofoffice BP monitoring, preferably using 24-hour ABPM. ${ }^{6-10}$ If $\mathrm{ABPM}$ is not available, or not tolerated, standardized home BP monitoring (HBPM) may be a substitute. ${ }^{6-10}$

Are primary care clinics adequately prepared to implement these recommendations for accurate OBPM and out-of-office BP monitoring for the 70 million patients with hypertension in the United States? ${ }^{11}$ Effective implementation of these interventions requires the use of OBPM and HBPM devices validated for accuracy by international protocols, ${ }^{12}$ training and subsequent monitoring of both clinic staff and patients in correct OBPM and HBPM protocols, ${ }^{13,14}$ convenient access to 24-hour ABPM services, ${ }^{15,16}$ and, optimally, use of an electronic health record (EHR) or electronic registry that can identify and track hypertension patients and their HBPM values. ${ }^{17}$

Utah formed the Utah Million Hearts Coalition (UMHC) as part of the national Million Hearts initiative to prevent 1 million heart attacks and strokes by $2017 . .^{18}$ The UMHC is a multistakeholder group of health care and public health entities, including subject matter experts in hypertension care, with a mission to prevent heart attacks and strokes in Utah through improved clinical care and accurate BP measurement and control in health care settings and at home. The objective of this descriptive study, led by the UMHC, was to assess the policies and procedures currently in place in Utah primary care clinics related to in-office and out-of-office BP measurement, and to identify gaps between current practices and the 2015 USPSTF diagnosis guidelines.

\section{Methods}

\section{Assessment}

A descriptive assessment of primary care clinics in Utah was conducted to determine the extent to which clinics throughout the state have policies and processes in place to ensure appropriate $\mathrm{BP}$ measurement and hypertension diagnosis. The UMHC developed a questionnaire to obtain clinic-level information on self-reported OBPM technique, ABPM availability, and HBPM patient instructional materials and processes. Because a broad range of processes are involved in the accurate diagnosis of hypertension, and because no one person in the clinic would likely be able to accurately answer all parts of the questionnaire, the assessment was designed to be completed by a team. Clinics were instructed to include, at a minimum, a medical assistant or registered nurse, a primary care physician, and an office manager or patient services representative. Questions were primarily quantitative and used either a yes/no response or a Likert scale, with responses ranging from "never" to "always" (see online Appendix).

The Utah Department of Health Institutional Review Board determined that the assessment collected information on professional opinions and not patient-specific data. The institutional review board reviewed the study proposal and deemed it to be exempt, in particular because the purpose of the assessment was quality improvement.

The questionnaire was drafted in early 2015 and administered to Utah primary clinics from April through August 2015. The UMHC was aware of the USPSTF draft document that was open for comment in late 2015, during questionnaire development. The assessment was pilot tested by 5 clinics, and questions were modified to improve clarity, as needed. Data from pilot clinics were not included in the final analysis.

A list of all known Utah primary care clinics was compiled. Lists were obtained from the Division of Professional Licensing, HealthInsight (Utah's quality innovation network-quality improvement organization), the Utah Health Information Exchange database, and local health system websites. UMHC partners work closely with most practices in the state and are aware of practice types. Clinics that practice family medicine, general practice, internal medicine, and geriatric medicine were included. A total of 398 primary care clinics were identified for the study. To ensure that clinic eligibility requirements were met, a screening question was included at the start of the assessment: "Does your practice provide primary care and treatment for patients with hypertension?" A summary of the clinic enrollment process is illustrated in Figure 1.

The assessment was conducted electronically using the online survey software Qualtrics, and links 
Figure 1. Flow of participants in study.

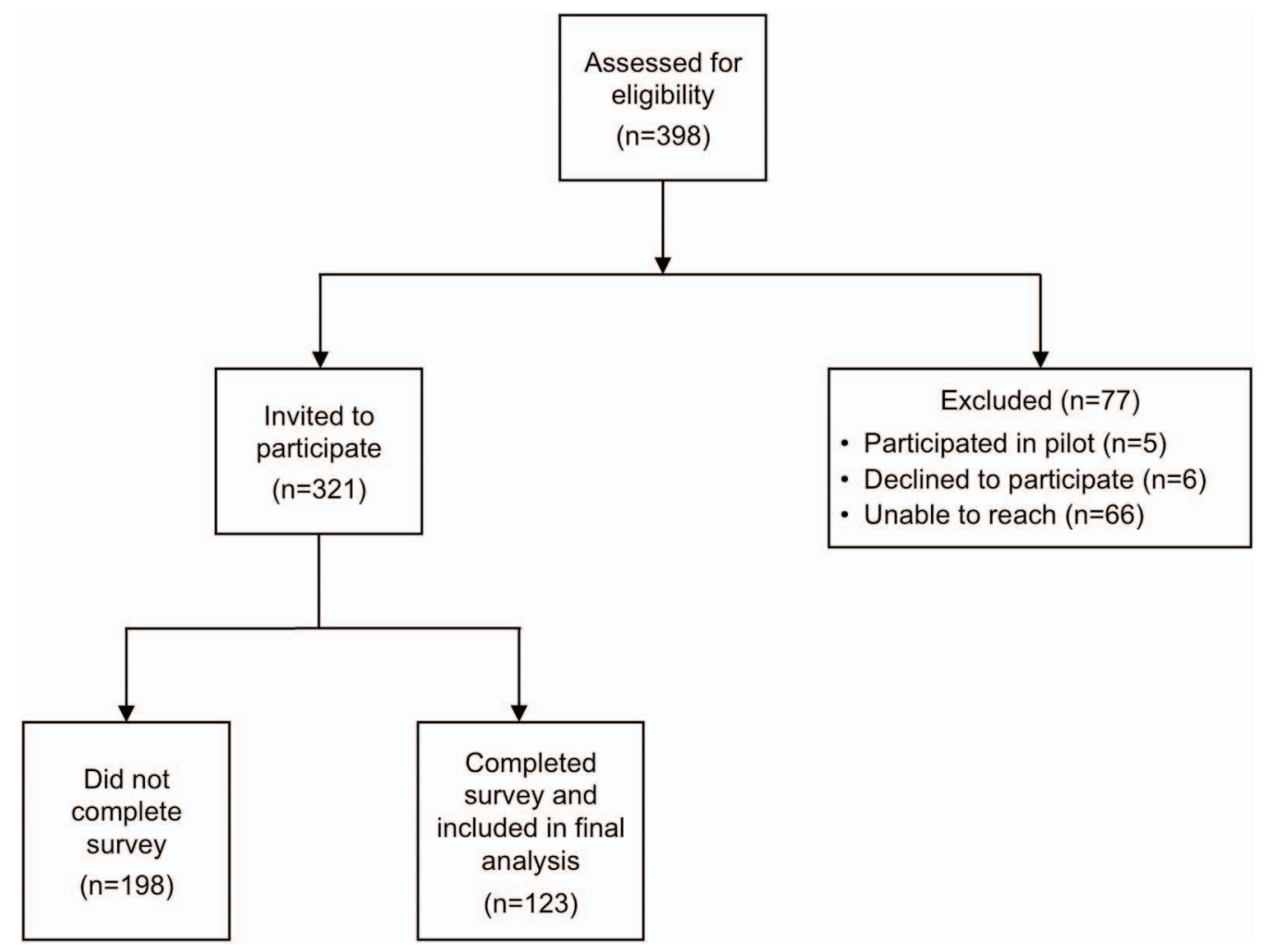

were sent to all clinics that provided a valid E-mail address. In total, 321 clinics provided a valid E-mail address and were used as the sample frame for the study. Only completed questionnaires were included in the analysis. A total of 198 clinics either did not begin, or began but did not complete, the questionnaire, whereas 123 clinics (38.3\%) completed the questionnaire. Although clinics were instructed to complete the assessment as a physician office team, only 1 in 4 clinics included all the requested team members in completing the questionnaire.

\section{Data Analysis}

UMHC assessment was completed on August 30, 2015; the USPSTF officially released its recommendations online on October 3, 2015. ${ }^{6}$ We reviewed our questionnaire and identified 10 questions from our assessment that were relevant to the USPSTF guidelines. Data were then reviewed to better understand the extent to which the clinics were currently in compliance with the recommendations for OBPM, ABPM, and HBPM. Self-reported adherence to the recommendations was measured as a 2 -category vari- able (adherent to/not adherent to recommendations). Clinics reporting "always" or "most of the time" to the Likert scale questions, or "yes" to the yes/no questions, were considered adherent to the recommendations. Descriptive analyses were used to determine the percentage of clinics that adhered to the recommendations. Recognizing that clinics that are part of a larger health care system with a hospital affiliation may have greater capacity to adhere to the recommendations than those in independent or solo clinics, we considered integration as a potential explanatory factor in recommendation compliance. Integration was measured as a 2 -category variable: (1) low $=$ not integrated with a health system affiliated with a hospital, and (2) high = integrated with a health system also affiliated with a hospital. We therefore examined the number of recommendations adhered to for each level of integration. Three categories were used: 0 to 4 (lowest), 5 to 7 (middle), and 8 to 10 (highest). The Fisher's exact test was used to determine the association between the level of integration and adherence to the USPSTF recommendations. 
Table 1. Characteristics of Responding Clinics Compared to All Utah Primary Care Clinics

\begin{tabular}{lcc}
\hline Clinic Characteristics & $\begin{array}{c}\text { Respondents } \\
(\mathrm{n}=123)\end{array}$ & $\begin{array}{c}\text { Utah Primary } \\
\text { Care Clinics } \\
(\mathrm{n}=398)\end{array}$ \\
\hline Clinic type & & \\
Family medicine & $83(67.5)$ & $252(63.3)$ \\
General practice & $12(9.8)$ & $10(2.5)$ \\
Internal medicine & $19(15.4)$ & $54(13.6)$ \\
Geriatrics & $3(2.4)$ & $7(1.8)$ \\
Multispecialty & $3(2.4)$ & $41(10.3)$ \\
Other & $3(2.4)$ & $34(8.5)$ \\
Total & $123(100.0)$ & $398(100.0)$ \\
Geographic density & & $243(61.1)$ \\
Urban & $76(61.8)$ & $155(38.9)$ \\
Rural/frontier & $47(38.2)$ & $398(100.0)$ \\
Total & $123(100.0)$ & \\
Integration level* & & $275(69.1)$ \\
Low & $57(46.3)$ & $123(30.9)$ \\
High & $66(53.7)$ & $398(100.0)$ \\
Total & $123(100.0)$ & \\
\hline
\end{tabular}

Data are $\mathrm{n}(\%)$.

*Low integration indicates a solo, independent clinic or a clinic that is part of a health care system that does not include a hospital. High integration represents a clinic that is part of a health care system that includes a hospital.

\section{Results}

In total, 123 primary care clinics completed the questionnaire (38.3\% response rate) and were included in the final analysis. The respondent profile was similar to the descriptive characteristics of the state of Utah with respect to geographic density and practice type, but clinics considered to be highly integrated had a higher response rate than clinics with low integration (Table 1).

The characteristics of the respondents are outlined in Table 2. The clinics were likely to be urban, family medicine, or groups with $>2$ providers. More than half of the respondents $(53.7 \%)$ were classified as highly integrated clinics.

We examined the extent to which clinics currently complied with the USPSTF recommendations for OBPM, HBPM, and ABPM based on responses to relevant assessment questions. Table 3 displays the USPSTF recommendations, the associated questions from our assessment, and the percentage of clinics that adhered to the recommendations. Recommendations were divided into 2 categories: (1) those that pertained to accurate OBPM techniques and (2) those used to confirm the diagnosis of hypertension with out-of-office BP
Table 2. Characteristics of Clinics Responding to Assessment

\begin{tabular}{|c|c|}
\hline Practice Characteristics & No. (\%) \\
\hline \multicolumn{2}{|l|}{ Setting } \\
\hline Federally qualified health center & $20(16.3)$ \\
\hline Hospital-based practice & $3(2.4)$ \\
\hline University-based practice & $11(8.9)$ \\
\hline Group practice ( $>2$ providers) & $61(49.6)$ \\
\hline Small or solo practice ( 1 or 2 providers) & $22(17.9)$ \\
\hline School-based community clinic & $2(1.6)$ \\
\hline Other & $4(3.3)$ \\
\hline Total & $123(100.0)$ \\
\hline \multicolumn{2}{|l|}{ Practice type } \\
\hline Family medicine & $83(67.5)$ \\
\hline General practice & $12(9.8)$ \\
\hline Internal medicine & $19(15.4)$ \\
\hline Geriatrics & $3(2.4)$ \\
\hline Multispecialty & $3(2.4)$ \\
\hline Other & $3(2.4)$ \\
\hline Total & $123(99.9)^{*}$ \\
\hline \multicolumn{2}{|l|}{ Practice size ${ }^{\dagger}$} \\
\hline $1-2$ & $40(32.5)$ \\
\hline $3-5$ & $35(28.5)$ \\
\hline $6-10$ & $30(24.4)$ \\
\hline$\geq 10$ & $15(12.2)$ \\
\hline Missing & $3(2.4)$ \\
\hline Total & $123(100.0)$ \\
\hline \multicolumn{2}{|l|}{ Geographic density } \\
\hline Urban & $76(61.8)$ \\
\hline Rural & $47(38.2)$ \\
\hline Total & $123(100.0)$ \\
\hline \multicolumn{2}{|l|}{ Integration level $^{\ddagger}$} \\
\hline Low & $57(46.3)$ \\
\hline High & $66(53.7)$ \\
\hline Total & $123(100.0)$ \\
\hline
\end{tabular}

*This total did not equal $100 \%$ because of rounding.

${ }^{\dagger}$ Full-time equivalent physicians and advanced practice clinicians.

${ }^{\ddagger}$ Low integration indicates a solo, independent clinic or a clinic that is part of a health care system that does not include a hospital. High integration indicates a clinic that is part of a health care system that includes a hospital.

monitoring. Only $58.5 \%$ of clinics self-reported the use of the mean of 2 OBPMs, and $57.7 \%$ reported allowing patients to rest at least 5 minutes before measuring BP. Only $25.2 \%$ of clinics reported having access to ABPM, and $36.6 \%$ had instructional materials to train patients in accurate HBPM.

Associations between the level of clinic integration and the number of USPSTF recommendations adhered to are displayed in Table 4. A 


\begin{tabular}{|c|c|c|}
\hline USPSTF Recommendation $^{6}$ & Utah Million Hearts Assessment Question & $\begin{array}{c}\text { Clinics Adherent to Recommendation, } \\
\% \text { (95\% CI) }\end{array}$ \\
\hline \multicolumn{3}{|l|}{$\begin{array}{l}\text { In-office blood pressure } \\
\text { measurement }\end{array}$} \\
\hline $\begin{array}{l}\text { Use the mean of } 2 \\
\text { measurements }\end{array}$ & $\begin{array}{l}\text { Q11: Repeat the measurement within } 1 \text { to } 2 \\
\text { minutes and use the mean of } 2 \text { measures }\end{array}$ & $58.5(49.7-67.4)$ \\
\hline $\begin{array}{l}\text { Measure while the patient is } \\
\text { seated }\end{array}$ & $\begin{array}{l}\text { Q5: Patient seated in a chair with back } \\
\text { support }\end{array}$ & $87.0(81.0-93.0)$ \\
\hline $\begin{array}{l}\text { Allow for } \geq 5 \text { minutes between } \\
\text { entry into office and } \mathrm{BP} \\
\text { measurement }\end{array}$ & $\begin{array}{l}\text { Q8: Measure BP after the patient has rested } \\
\text { quietly for } 5 \text { minutes before measurement }\end{array}$ & $57.7(48.9-66.6)$ \\
\hline $\begin{array}{l}\text { Use an appropriately sized } \\
\text { arm cuff }\end{array}$ & $\begin{array}{l}\text { Q10: Use a cuff size appropriate to the } \\
\text { patient's midarm circumference }\end{array}$ & $93.5(89.1-97.9)$ \\
\hline $\begin{array}{l}\text { Place the patient's arm at the } \\
\text { level of the right atrium }\end{array}$ & $\begin{array}{l}\text { Q7: Measure BP with the patient arm and } \\
\text { cuff at midsternal level }\end{array}$ & $84.6(78.1-91.0)$ \\
\hline \multicolumn{3}{|l|}{$\begin{array}{l}\text { Out-of-office hypertension } \\
\text { diagnosis confirmation }\end{array}$} \\
\hline $\begin{array}{l}\text { ABPM may be used to } \\
\text { confirm a diagnosis after } \\
\text { initial screening }\end{array}$ & $\begin{array}{l}\text { Q18: Practice has access to 24-hour ABPM } \\
\text { studies }\end{array}$ & $25.2(17.4-33.0)$ \\
\hline \multirow{3}{*}{$\begin{array}{l}\text { HBPM may be used to } \\
\text { confirm a diagnosis after } \\
\text { initial screening }\end{array}$} & $\begin{array}{l}\text { Q15: Practice has a written policy for training } \\
\text { patients on accurate HBPM }\end{array}$ & $27.6(19.6-35.7)$ \\
\hline & $\begin{array}{l}\text { Q16: Staff distribute materials for HBPM for } \\
\text { newly diagnosed patients or those with } \\
\text { uncontrolled hypertension }\end{array}$ & $36.6(28.0-45.2)$ \\
\hline & $\begin{array}{l}\text { Q17: Practice designates at least } 1 \text { member of } \\
\text { the care team to provide individualized } \\
\text { training in accurate HBPM }\end{array}$ & $48.8(39.8-57.7)$ \\
\hline $\begin{array}{l}\text { Recommends use of a regular } \\
\text { screening interval }\end{array}$ & $\begin{array}{l}\text { Q23: Practice has a system to alert patients } \\
\text { with uncontrolled hypertension of a missed } \\
\text { appointment or overdue BP check }\end{array}$ & $55.3(46.4-64.2)$ \\
\hline
\end{tabular}

ABPM, 24-hour ambulatory blood pressure monitoring; CI, confidence interval; BP, blood pressure; HBPM, home blood pressure monitoring; USPSTF, US Preventive Services Task Force.

Table 4. Level of Clinic Integration and Number of US Preventive Services Task Force Recommendations Adhered to by Clinic

\begin{tabular}{lcrrr}
\hline & \multicolumn{3}{c}{$\begin{array}{c}\text { Number of USPSTF } \\
\text { Recommendations Adhered To }\end{array}$} & \\
\cline { 2 - 4 } $\begin{array}{l}\text { Lntegration } \\
\text { Level }\end{array}$ & $0-4$ & $5-7$ & $8-10$ & Total \\
\hline Low & $20(35.1)$ & $31(54.4)$ & $6(10.5)$ & $57(100.0)$ \\
High & $17(25.8)$ & $25(37.9)$ & $24(36.4)$ & $66(100.0)$ \\
Total & $37(30.1)$ & $56(45.5)$ & $30(24.4)$ & $123(100.0)$ \\
\hline
\end{tabular}

Data are $\mathrm{n}(\%)$.

Differences are statistically significant $(P<.01)$.

*Low integration indicates a solo, independent clinic or a clinic that is part of a health care system that does not include a hospital. High integration represents clinics that are part of a health care system that includes a hospital.

USPSTF, US Preventive Services Task Force.

statistically significant association exists between integration and the number of recommendations adhered to by clinics. A higher percentage of clinics that were highly integrated adhered to 8 to 10 recommendations compared with clinics with low integration (36.4\% and $10.5 \%$, respectively).

\section{Discussion}

The 2015 USPSTF Recommendations for Screening for High BP in Adults ${ }^{6}$ and other recent international guidelines ${ }^{7-10}$ aim to improve the accuracy of hypertension diagnosis (1) by using correct OBPM technique to avoid the frequent overestimation and occasional underestimation of office BP resulting from incorrect technique, ${ }^{1-3}$ and (2) by confirming the diagnosis of hypertension with outof-office BP measurement using 24-hour ABPM or HBPM to detect isolated office hypertensionknown as "white-coat hypertension"-that is present in $30 \%$ of patients with elevated office BP. ${ }^{4,5}$ Unfortunately, our assessment of primary care practices in Utah confirms previous studies demonstrating incorrect OBPM as a widespread phenomenon in clinical practice. Our findings also 
suggest there likely are major challenges to the effective implementation of out-of-office BP measurement with either ABPM or HBPM.

These gaps identified with Utah practices are not surprising. Use of ABPM in the United States, as assessed by Medicare claims, is indeed very low, ${ }^{19}$ likely because of a combination of limited availability, inadequate reimbursement by payers, ${ }^{20}$ and limited clinician knowledge about ABPM as an important diagnostic tool. In fact, $80 \%$ of a small sample of 143 primary care physicians in a large urban city (Portland, Oregon) reported access to ABPM, although fewer than half reported using it. $^{21}$

The accuracy of HBPM performed in realworld settings is of concern. Recent studies indicate that only $10 \%$ to $17 \%$ of clinicians provide HBPM training that is even minimally adherent to guidelines for accurate measurement, ${ }^{22-24}$ and fewer than $20 \%$ of patients may be sufficiently adherent to the recommended HBPM technique to ensure reliable HBPM. ${ }^{14,25,26}$ Compared with ABPM, HBPM requires a substantial commitment to training by both clinics and patients, and it may require individual, face-to-face instruction for optimal results. ${ }^{13,14,26}$ Our assessment of Utah primary care clinics found similar concerns about their current delivery of patient training to facilitate accurate HBPM. Only $27.6 \%$ had a written policy for training patients in HBPM, 36.6\% distributed written HBPM instructional materials, and just $48.8 \%$ had designated a team member to provide individual HBPM instruction.

This study had several limitations. First, UMHC conducted the assessment before the USPSTF hypertension assessment document was finalized, and thus the actual questionnaire was not perfectly aligned with the final wording of the USPSTF guidelines. Second, 198 primary care clinics did not complete the assessment, which could have introduced bias; however, our response rate $(38.3 \%)$ seems to be within the range for current office practice surveys. ${ }^{27,28}$ Third, our results show a higher response rate from larger, highly integrated health systems than from smaller practices. This may be the result of greater capacity by staff to complete the assessment at these sites and/or greater organizational interest in the topic. In addition, some clinics did not complete the assessment using all team members requested, which could lead to incomplete descriptions of office practices. Finally, the self-report aspect of the questionnaire may have introduced bias toward overestimating adherence to recommended BP measurement practices as a result of social desirability. Physician self-report and peer report may not accurately reflect actual adherence to best practices in clinical settings. ${ }^{29}$ In light of these limitations, we believe our estimates of BP measurement practices are likely to overestimate adherence to guideline recommendations.

Our findings point to the low use of both $A B P M$ and HBPM, both of which may be cost-beneficial in diagnosing hypertension from both societal ${ }^{30}$ and payer $^{31}$ perspectives by identifying only sustained hypertension in and out of the office and by eliminating subsequent unnecessary treatment, potential adverse events from overtreatment, and unnecessary follow-up costs. The 2015 USPSTF recommendations favor ABPM over HBPM for diagnosing hypertension because of a larger number of supporting studies, ${ }^{4,6}$ although a recent systematic review found no definitive evidence to prefer 1 over the other. ${ }^{32}$ ABPM may be more time-efficient for clinics to diagnose hypertension because it does not require intensive patient training in performing HBPM.

This study suggests several ways that physicians can facilitate implementation of the 2015 USPSTF recommendations for hypertension diagnosis. First, OBPM may be improved by the use of automated OBPM (AOBPM) using validated devices that automatically perform and average 3 to 6 measurements at 1 -minute intervals while patients are isolated, alone in an examination room or in a quiet corner of the waiting room. ${ }^{33,34}$ AOBPM eliminates a number of technical errors in manual $\mathrm{BP}$ measurement, is a better predictor of cardiovascular outcome than OBPM, and substantially reduces "white-coat hypertension," thereby reducing the need for out-of-office BP measurement. ${ }^{1,2,33,34} \mathrm{An}$ unobserved AOBPM reading of 135/85 $\mathrm{mmHg}$ carries a cardiovascular risk equivalent to that of an observed guideline-quality office BP measurement of $140 / 90 \mathrm{mmHg} .{ }^{34}$ Second, ABPM availability must be expanded, and this will require adjustment of third-party payer policies as well as primary care clinic education. ${ }^{20}$ Third, primary care clinics must be supported to develop HBPM patient training programs. HBPM data collection schemes ${ }^{35-39}$ and EHR systems that can easily integrate HBPM measurements into clinic workflow will be important. ${ }^{17}$ 
Finally, continued support of office practices to use their EHRs to monitor population-wide hypertension control rates and to target the groups at highest risk is imperative. State and local health departments and quality improvement organizations, perhaps under the umbrella of the national Million Hearts campaign, which is sponsored jointly by the Centers for Disease Control and Prevention and Centers for Medicare and Medicaid Services, can, we hope, help bring infrastructure to primary care clinics to help implement the 2015 USPSTF guidelines for hypertension diagnosis.

We would like to thank the Utah Million Hearts Coalition, sponsored by the Utah Department of Health, and Nicole Bissonette, MPH, MCHES, Program Manager Healthy Living through Environment, Policy and Improved Clinical Care Program (EPICC) for their support of this work.

To see this article online, please go to: http://jabfm.org/content/ 30/2/170.full.

\section{References}

1. Myers MG. The great myth of office blood pressure measurement. J Hypertens 2012;30:1894-8.

2. Myers MG, Godwin M, Dawes M, Kiss A, Tobe SW, Kaczorowski J. Measurement of blood pressure in the office: recognizing the problem and proposing the solution. Hypertension 2010;55:195-200.

3. Powers BJ, Olsen MK, Smith VA, Woolson RF, Bosworth HB, Oddone EZ. Measuring blood pressure for decision-making and quality reporting: where and how many measures? Ann Intern Med 2011;154:781-8.

4. Piper MA, Evans CV, Burda BU, Margolis KL, O'Connor E, Whitlock EP. Diagnostic and predictive accuracy of blood pressure screening methods with consideration of rescreening intervals: a systematic review for the U.S. Preventive Services Task Force. Ann Intern Med 2015;162:192-204.

5. Gorostidi M, Vinyoles E, Banegas JR, de la Sierra A. Prevalence of white-coat and masked hypertension in national and international registries. Hypertens Res 2015;38:1-7.

6. Siu AL; U.S. Preventive Services Task Force. Screening for high blood pressure in adults: U.S. Preventive Services Task Force Recommendation Statement. Ann Intern Med 2015;163:778-86.

7. Leung AA, Nerenberg K, Daskalopoulou SS, et al. Hypertension Canada's 2016 Canadian Hypertension Education Program guidelines for blood pressure measurement, diagnosis, assessment of risk, and treatment of hypertension. Can J Cardiol 2016;32: 569-88.

8. Parati G, Stergiou G, O'Brien E, et al. European society of hypertension practice guidelines for am- bulatory blood pressure monitoring. J Hypertens 2014;32:1359-66.

9. Sharman JE, Howes FS, Head GA, et al. Home blood pressure monitoring: Australian expert consensus statement. J Hypertens 2015;33:1721-8.

10. Krause T, Lovibond K, Caulfield M, McCormack T, Williams B. Management of hypertension: summary of national institute for health and clinical excellence (NICE) guidance. BMJ 2011;343:d4891.

11. Yoon SS, Fryar CD, Carroll MD. Hypertension prevalence and control among adults: United States, 2011-2014. NCHS Data Brief 2015;(220):1-8.

12. Campbell NR, Berbari AE, Cloutier L, et al. Policy statement of the World Hypertension League on noninvasive blood pressure measurement devices and blood pressure measurement in the clinical or community setting. J Clin Hypertens (Greenwich) 2014;16:320-2.

13. Sendra-Lillo J, Martinez-Martinez F, Garcia-Corpas JP, et al. Validity of home blood pressure measurements manually registered by patients after an educational session provided by community pharmacists. Blood Press Monit 2015;20:232-6.

14. Milot JP, Birnbaum L, Larochelle P, et al. Unreliability of home blood pressure measurement and the effect of a patient-oriented intervention. Can J Cardiol 2015;31:658-63.

15. Bloch MJ, Basile JN. Ambulatory blood pressure monitoring-an idea whose time has come. J Am Soc Hypertens 2015;10:89-91.

16. Shimbo D, Abdalla M, Falzon L, Townsend RR, Munther P. Role of ambulatory and home blood pressure monitoring in clinical practice: a narrative review. Ann Intern Med 2015;163:691-700.

17. Goldstein KM, Zulig LL, Bosworth HB, Oddone EZ. Consideration of out-of-office blood pressure monitoring in hypertension management. J Clin $\mathrm{Hy}-$ pertens (Greenwich) 2016;18:381-2.

18. Million Hearts. About Million Hearts. Available from: http://millionhearts.hhs.gov/about-million-hearts/ index.html. Accessed March 13, 2016.

19. Shimbo D, Kent ST, Diaz KM, et al. The use of ambulatory blood pressure monitoring among Medicare beneficiaries in 2007-2010. J Am Soc Hypertens 2014;8:891-7.

20. Kent ST, Shimbo D, Huang L, et al. Rates, amounts, and determinants of ambulatory blood pressure monitoring claim reimbursements among Medicare beneficiaries. J Am Soc Hypertens 2014; 8:898-908.

21. Carter BU, Kaylor MB. The use of ambulatory blood pressure monitoring to confirm a diagnosis of high blood pressure by primary care physicians in Oregon. Blood Press Monit 2016;21:95-102.

22. Boivin J, Tsou-Gaillet T, Fay R, et al. Influence of the recommendations on the implementation of home blood pressure measurement by French gen- 
eral practitioners: a 2004-2009 longitudinal survey. J Hypertens 2011;29:2105-15.

23. Logan AG, Dwnai A, McIsaac WJ, Irvine MJ, Tisler A. Attitudes of primary care physicians and their patients about home blood pressure monitoring in Ontario. J Hypertens 2008;26:446-52.

24. Obara T, Ohkubo T, Fukunaga H, et al. Practice and awareness of physicians regarding home blood pressure measurement in Japan. Hypertens Res 2010;33:428-34.

25. Flacco ME, Manzoli L, Bucci M, et al. Uneven accuracy of home blood pressure measurement: a multicentric survey. J Clin Hypertens 2015;17:638-43.

26. Levy J, Gerber LM, Wu X, Mann SJ. Non-adherence to recommended guidelines for blood pressure measurement. J Clin Hypertens (Greenwich) 2016; 18:1157-61.

27. Braithwaite D, Emery J, De Lusignan S, Sutton S. Using the Internet to conduct surveys of health professionals: a valid alternative? Fam Pract 2003;20: 545-51.

28. Dobrow MJ, Orchard MC, Golden B, et al. Response audit of an Internet survey of health care providers and administrators: implications for determination of response rates. J Med Internet Res 2008; 10:e30.

29. Saturno PJ, Palmer RH, Gascon JJ. Physician attitudes, self-estimated performance and actual compliance with locally peer-defined quality evaluation criteria. Int J Qual Health Care 1999;11:487-96.

30. Lovibond K, Jowett S, Barton P, et al. Cost-effectiveness of options for the diagnosis of high blood pressure in primary care: a modelling study. Lancet 2011;378:1219-30.

31. Arrieta A, Woods JR, Qiao N, Jay SJ. Cost-benefit analysis of home blood pressure monitoring in hypertension diagnosis and treatment: an insurer perspective. Hypertension 2014;64:891-6.
32. Shimbo D, Abdalla M, Falzon L, Townsend RR, Muntron P. Studies comparing ambulatory bloodpressure and home blood pressure on cardiovascular disease and mortality outcomes: a systematic review. J Am Soc Hypertens 2016;10:224-34.

33. Myers MG. Automated office blood pressure-the preferred method for recording blood pressure. J Am Soc Hypertens 2016;10:194-6.

34. Myers MG, Kaczorowski J, Paterson JM, Dolovich $\mathrm{L}$, Tu K. Thresholds for diagnosing hypertension based on automated office blood pressure measurements and cardiovascular risk. Hypertension 2015; 66:489-95.

35. Sharman JE, Blizzard L, Kosmala W, Nelson MR. Pragmatic method using blood pressure diaries to assess blood pressure control. Ann Fam Med 2016; 14:63-9.

36. Postel-Vinay N, Bobrie G, Ruelland A, et al. Automated integration of home blood pressure assessment (Hy-Result software) versus physician's assessment: a validation study. Blood Press Monit 2016; 21:111-7.

37. Pickering TG, Miller NH, Ogedegbe G, et al. American Heart Association; American Society of Hypertension; Preventive Cardiovascular Nurses Association. Call to action on use and reimbursement for home blood pressure monitoring. Hypertension 2008;52:10-29.

38. Neeley E, Ayala C, Rashon L, et al. Where do we stand with home blood pressure monitoring use among adults with hypertension? J Am Soc Hypertens 2014;8(4 Suppl):e64.

39. Ostchega Y, Berman L, Hughes JP, Chet T, Chiappa MM. Home blood pressure monitoring and hypertension status among U.S. adults: the National Health and Nutrition Examination Survey (NHANES), 2009-2010. Am J Hypertens 2013;26:1086-92. 